Provided for non-commercial research and education use. Not for reproduction, distribution or commercial use.

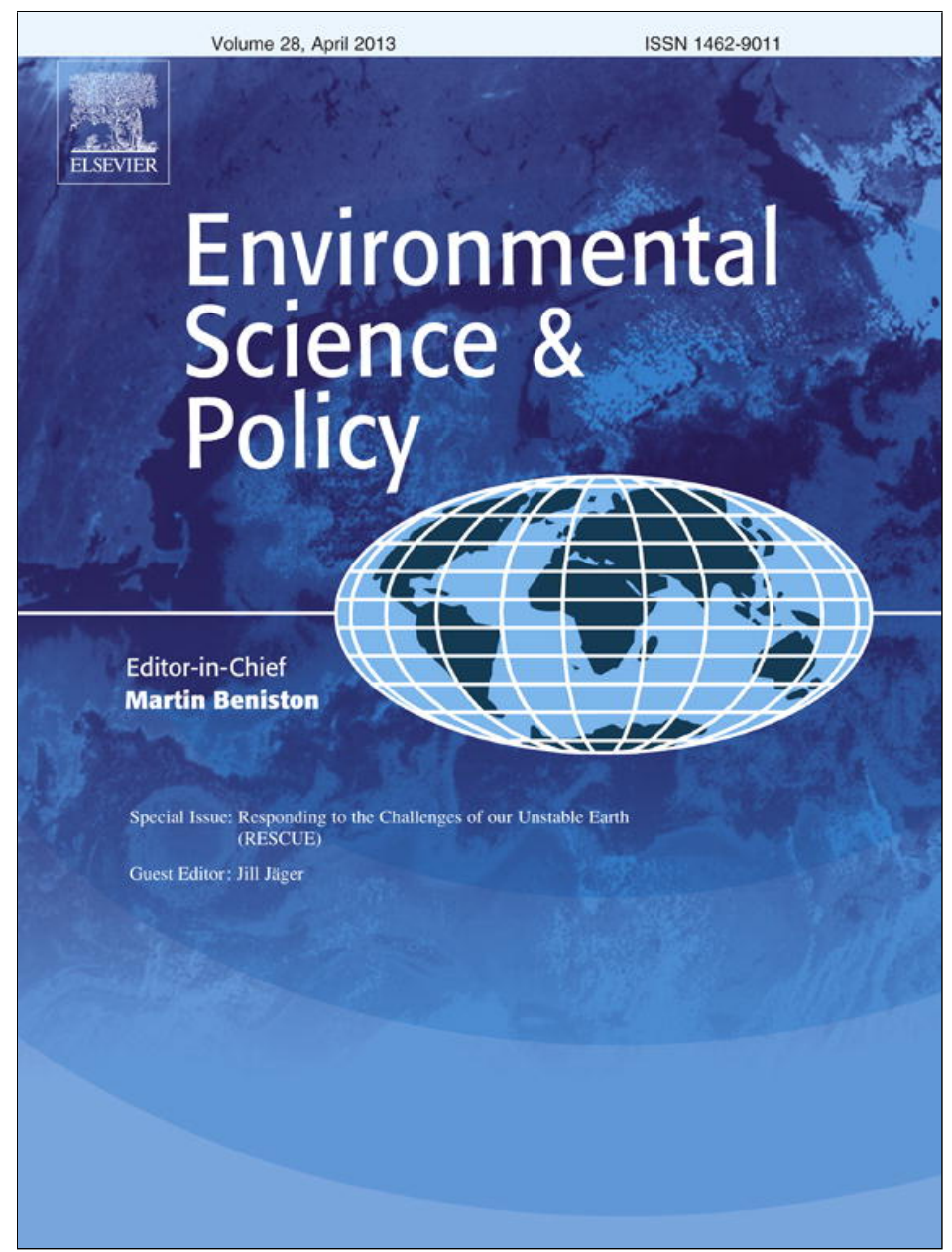

This article appeared in a journal published by Elsevier. The attached copy is furnished to the author for internal non-commercial research and education use, including for instruction at the authors institution and sharing with colleagues.

Other uses, including reproduction and distribution, or selling or licensing copies, or posting to personal, institutional or third party websites are prohibited.

In most cases authors are permitted to post their version of the article (e.g. in Word or Tex form) to their personal website or institutional repository. Authors requiring further information regarding Elsevier's archiving and manuscript policies are encouraged to visit:

http://www.elsevier.com/authorsrights 


\title{
Collaboration between the natural, social and human sciences in Global Change Research
}

\author{
Poul Holm ${ }^{a, *}$, Michael Evan Goodsite ${ }^{b}$, Sierd Cloetingh ${ }^{c}$, Mauro Agnoletti ${ }^{d}$, \\ Bedrich Moldan ${ }^{e}$, Daniel J. Lang ${ }^{f}$, Rik Leemans ${ }^{g}$, Joergen Oerstroem Moeller ${ }^{h}$, \\ Mercedes Pardo Buendía ${ }^{i}$, Walter Pohl ${ }^{j}$, Roland W. Scholz ${ }^{k}$, Andrew Sors ${ }^{l}$, \\ Bernard Vanheusden ${ }^{m}$, Kathryn Yusoff ${ }^{n}$, Ruben Zondervan ${ }^{\circ}$
}

\footnotetext{
${ }^{a}$ Trinity Long Room Hub Professor of Humanities, Trinity College Dublin, 2 College Green, Dublin, Ireland

${ }^{\mathrm{b}}$ Atmospheric Chemistry, Climate and Global Processes, Aarhus University, Birk Centerpark 15, DK-7400 Herning, Denmark

${ }^{c}$ Department of Earth Sciences, Utrecht University, Budapestlaan 4, 3584CD Utrecht, The Netherlands

${ }^{\mathrm{d}}$ Laboratory for Landscape and Cultural Heritage, Faculty of Agriculture, Via San Bonaventura 13, 50145 Firenze, Italy

${ }^{\mathrm{e}}$ Director of the Environment Center, Charles University, Prague, Czech Republic C11.210f, 21335 Lüneburg, Germany

${ }^{\mathrm{g}}$ Environmental System Analysis Group, Wageningen University, PO-Box 47, 6700AA Wageningen, The Netherlands Singapore

${ }^{\mathrm{i}}$ Department of Political Science and Sociology, Unversity Carlos III, Madrid, Spain

jUniversity of Vienna, Historical Institute, Universitätsring 1, 1010 Wien, Austria

${ }^{\mathrm{k}}$ ETH Zurich, Institute of Environmental Decisions, Natural and Social Science Interface, Switzerland

${ }^{1}$ Head of Brussels Office, EuroTech Universities Alliance, Square de Meeus 23, B-1000 Brussels, Belgium

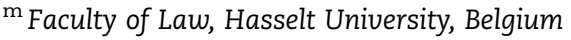

${ }^{\mathrm{n}}$ Lancaster Environment Centre, Lancaster University, UK

${ }^{\circ}$ Earth System Governance Project and Lund University, Sweden
}

${ }_{\mathrm{f}}^{\mathrm{f}}$ Institute of Ethics and Transdisciplinary Sustainability Research, Faculty Sustainability, Leuphana University Lüneburg, Scharnhorststr. 1,

${ }^{\mathrm{h}}$ Institute of Southeast Asian Studies, Singapore Adjunct Professor, Singapore Management University \& Copenhagen Business School,

\section{A R T I C L E I N F O}

Article history:

Received 30 January 2012

Received in revised form

16 May 2012

Accepted 12 November 2012

Published on line 23 December 2012

Keywords:

Global environmental change

Human impacts

Interdisciplinary research

Sciences and humanities

Programme funding

Research collaboration

\begin{abstract}
A B S T R A C T
In nearly all domains of Global Change Research (GCR), the role of humans is a key factor as a driving force, a subject of impacts, or an agent in mitigating impacts and adapting to change. While advances have been made in the conceptualisation and practice of interdisciplinary Global Change Research in fields such as climate change and sustainability, approaches have tended to frame interdisciplinarity as actor-led, rather than understanding that complex problems which cut across disciplines may require new epistemological frameworks and methodological practices that exceed any one discipline.

GCR studies must involve from their outset the social, human, natural and technical sciences in creating the spaces of interdisciplinarity, its terms of reference and forms of articulation. We propose a framework for funding excellence in interdisciplinary studies, named the Radically Inter- and Trans-disciplinary Environments (RITE) framework. RITE includes the need for a realignment of funding strategies to ensure that national and international research bodies and programmes road-map their respective strengths and identified areas for radical interdisciplinary research; then ensure that these areas can and
\end{abstract}

\footnotetext{
* Corresponding author. Tel.: +353876188039.

E-mail address: holmp@tcd.ie (P. Holm).

1462-9011/\$ - see front matter (C) 2012 Elsevier Ltd. All rights reserved. http://dx.doi.org/10.1016/j.envsci.2012.11.010
} 
are appropriately funded and staffed by talented individuals who want to apply their creative scientific talents to broader issues than their own field in the long term, rather than on limited scope (5 year and less) research projects. While our references are mostly to Europe, recommendations may be applicable elsewhere.

(C) 2012 Elsevier Ltd. All rights reserved.

\section{Introduction}

Global Change Research (GCR) is shorthand for studies of the Human and Earth System in the Anthroposcene. This paper is an invitation to all disciplines and domains to collaborate in a fully rounded and integrated view of human agency and the planetary environment. The Radically Inter- and Transdisciplinary Environments (RITE) framework offers a conceptual framework to help bridge the gaps between knowledge and action and link the past with the future. Second, it gives greater attention to biogeophysical dimensions in social sciences, to cultural narratives and humanities views in ecology, and to ecological approaches to humanistic studies. Third, it delivers a strongly defined set of concepts, theory and research goals to shape pan-European (as opposed to merely national) research. Fourth, it promotes the active and practical connection of academic and scientific communities with civil, commercial and political society. Fifth, radical interdisciplinary research can inform and steer policy makers in an overarching way (instead of informing on very specific scientific questions). Finally, it forms a link between long term historical and current environmental understandings of landscape as the basis for robust future-looking scenarios.

The IPCC observed in 2007 that the world already has at its disposal the technologies for climate change mitigation and adaptation but that the big challenge is related to human acceptance of costs and socio-cultural consequences.

The RITE framework when applied therefore helps enable research in grand research questions such as:

- How can we explain variation in resource use?

- What explains different societies' willingness and ability to mitigate and adapt to the consequences of environmental change?

- What factors - political, institutional, social, cultural, cognitive - shape the implementation and use of different sources of renewable energy?

- What unintended consequences do policies implemented to address grand challenges have on society?

- How can research projects actively contribute to societal transformation processes?

In nearly all domains of Global Change Research (GCR), the role of humans is a key factor as a driving force, a subject of impacts - and an agent in mitigating impacts and adapting to change. Similarly human and social sciences benefit from embedding anthropogenic research questions in an understanding of environmental forces. This paper proposes a strategic vision to break down the individual and institutional barriers that hamper collaboration between the physical, natural, medical and social sciences and humanities in global change studies.
Although recent work has examined the factors associated with disciplinary and interdisciplinary research collaboration (van Rijnsoever et al., 2011) to efficiently address the issues above, a common theoretical and operational framework is needed for interdisciplinary research issues.

\section{Why the present system is not fit for dealing with global change issues}

Although good examples of interdisciplinary research exist, the present situation is not fit for dealing with global change issues. Collaboration across faculty divides is difficult because of institutional disincentives. In particular, while it is widely recognised that Global Change studies need to benefit from collaboration between human and social sciences on the one hand and natural and technical sciences on the other hand, such collaboration happens only in very few cases. At most universities and other (academic) research institutions faculties of neighbouring disciplines have the upper hand. Some of this is even institutionalised or nationalised. For example, publically funded European universities generally receive greater funding for a graduating natural/polytechnical sciences or Health Sciences student than for social sciences or humanities. While this is meant to allow for greater costs associated with laboratory studies, the result is that many interdisciplinary programmes in GCR are anchored in natural sciences or polytechnical faculties.

Furthermore, various important disciplines, mainly social and human, are too often overlooked or neglected as a science, such as law, architecture, history, literature, communication, sociology and psychology. These are important disciplines to fully understand earth systems and human motivation and to guide decision-makers. However, they are not routinely seen as fundamental to give policy advice. Proponents of interdisciplinary research at times relegate human and social science research to an auxiliary, advisory, and essentially nonscientific status. An example is the conceptualization of social science in the 23 questions that the Global Analysis, Integration and Modelling task force of the International GeosphereBiosphere Programme (IGBP) has put forward as overarching questions for earth system analysis (Schellnhuber and Sahagian, 2002). However, the social science questions are not viewed as part of the 'analytical' questions (which are exclusively related to natural science), but as part of the 'strategic' or 'normative' questions hence reducing social sciences to its policy-oriented, advisory dimensions (Biermann et al., 2009; IHDP, 2007). Similar conclusions might be drawn from the latest ICSU visioning process, which appears to be dominated by a natural science focus (Reid et al., 2010).

On top of that, interdisciplinarity is too often not integrated from the start. Definition of the problem often sets the terms of engagement, expected outcomes, who is involved, etc. This 
helps ensure that a joint research or conceptual framework is developed with all the necessary commonalities, such as semantics and a common agenda right through to the final evaluation of research. When for example legal researchers are involved right from the beginning, they can ensure that the scientific results of a multidisciplinary research can be translated into concrete policy recommendations. The natural, human and social sciences should therefore be integrated from day one.

Barriers to RITE include a lack of strategic focus by universities, a conservative educational system, lack of formal criteria emphasising radical interdisciplinarity by research councils, cultural and career barriers, lack of inter-industry linkage, and developmental issues.

\subsection{Lack of strategic focus by universities}

Many universities have initialised collaborative research programmes in Global Change Research, and most recognise the need to draw on strengths from all relevant research fields. However, we believe it is fair to say that most of these initiatives are hardly game-changing but rather represent recognition of the challenge. Incentive structures are greatly absent and when they are present, with few exceptions (such as ASU http://schoolofsustainability.asu.edu/, UBC http:// www.sustain.ubc.ca/, Leuphana http://www.leuphana.de/ en/faculty-sustainability.html, they are symbolically, rather than institutionally changing.

\subsection{Conservative educational system}

Many universities have remained as "business as usual" in the current societal environment and this has led US journalists and scholars to question: "Will America's universities go the way of its car companies?" (Schumpeter, Declining by Degree: Will America's Universities go the way of Its Car Companies. The Economist, September 2nd, 2010; Economist.com/blogs/schumpeter (http://www.economist. com/blogs/schumpeter). While some universities should receive credit for their strategic focus on educating the next generation of citizens able to contribute effectively to society in a changing global environment, many are still practicing "business as usual" and this [lack of] focus is a barrier to successful interdisciplinary global research. Students need to be brought up in an environment where they feel empowered to be interdisciplinary (cf the Curriculum Reform Initiative http://curriculumreform.org/). At the same time, the institutions cannot be too fixed in their methodology or their horizons (Cloetingh et al., 2007).

\subsection{Training barriers}

Interdisciplinary programmes are promoted but it is not always evident that the students have success. Ultimately a standard training and career path predictive of success for those who desire collaboration has yet to be defined, though most would state and expect that excellence as a foundation in a discipline is a pre-requisite to collaborative excellence. Sometimes researchers are just in the right place at the right time and are willing to transgress institutional boundaries.
Some are also developing business and otherwise engaging in entrepreneurship. Successful students are able to make their own career choices, not just accept what is available and demonstrate the willingness to take risks.

\subsection{Lack of formal criteria emphasising radical interdisciplinarity by research councils}

National and international research councils and funding agencies play a critical role in defining areas of research that support a "broad church" approach to interdisciplinarity. While most councils and agencies actively promote interdisciplinarity, Global Change Research programmes founded on radical interdisciplinarity are few and far between.

\subsection{Cultural and career barriers}

Career barriers can be challenged in the short term by introducing positive measures to increase recruitment and mobility of RITE scientists while cultural barriers and path dependencies are likely to persist for a longer time.

\subsection{Industry and civil society linkages}

Interaction between research and industry and civil society is key to slowing down man-made global climate change. In 2010 The European Institute of Innovation and Technology (EIT) (an EU body established in March 2008) launched so called knowledge-innovation centres (KICs) where this type of interaction is promoted. The way that these KICs were selected and are to be managed predicts that they will have success only if they are able to integrate and gain synergies across the academic industrial border and the scales they work with. Besides university-industry collaborations, mutual learning processes with other relevant societal group, such as civil society organisations, policy makers and the public at large are crucial to foster sustainability transitions (see e.g. Scholz et al., 2006; Lang et al., 2012 or Spangenberg, 2011).

\subsection{Developmental issues}

Ensuring prosperity in developing countries are high-priority needs for advanced interdisciplinary studies, and much work lies ahead with regard to environmental justice and the linkages of the Global Eenvironmental Change and Human Development agendas.

In conclusion, a great deal of support can be mobilised, many ingredients are there, to develop a long-term stable framework for further integration but at present the overall picture is one of fragmentation rather than concerted action and shared research facilities. The dramatically increased mobility of European researchers and dual training of PhD students puts Europe in a strong position for this endeavour.

Overall, an effective way has to be found to promote best practices between research organisations to fund activities that could better contribute to solving the Global Change challenges. The important elements for future action for funding bodies such as research councils are: 
- Actively promote excellence from the junior researcher to the senior.

- Actively promote cross-professional cooperation and fostering industrial representation at global change meetings and initiatives.

- Define areas of research that support a "broad church" approach to interdisciplinarity.

\section{Global Change Research as a challenge to universities}

In positive terms, we may talk of Global Change Research as a University Challenge which increasingly is stimulating universities to change, graphically represented in Fig. 1 . In the traditional university, disciplinary knowledge production is based on a division of labour along faculty and disciplinary divides. Central shared facilities are typically restricted to library and administrative functions. The RITE framework is based on the observation that disciplines need to be and indeed increasingly are converging, blending data and information across disciplinary divides. Shared facilities are increasingly collaborative, devolved, and scalable based on a digital platform. We believe that the success of the university as a producer of knowledge depends on its ability to develop the RITE supporting infrastructure, education and research training mechanisms.

Disciplinary specialisation has been the basis of scientific progress certainly since the nineteenth century. Karl Pearson described the need for it in his book The Grammar of Science (1892), and disciplinary specialisation will remain one of the most productive divisions of knowledge labour in the future (as described for example in the medical field by Gelfand, 1976 and discussed in many other studies). However, real-world problems do not conform to disciplinary divides. Large problems call for contributions from many angles, and very often complicated problems cannot be understood and indeed solved by one scientific approach nor by science alone. GCR is one such field that eminently requires the contribution by academics from many disciplines. The need for multidisciplinarity - collaboration between several disciplines - is therefore a given and as noted in a January 2011 white paper from MIT (http://web.mit.edu/dc/Policy/MIT\%20White\%20 Paper\%20on\%20Convergence.pdf, accessed 20.10.11) the Health Sciences maybe much further ahead of other areas in recognizing this, but still emphasise the need for "convergence" in complex research issues a viewpoint collaborated in an Inogen Working paper from April 2011 (http://www. genomicsnetwork.ac.uk/media/Innogen\%20Working\%20Paper \%2090.pdf, accessed 20.10.11).

Various terms are used to describe interfaces between sciences. While calls for research funding often cite 'interdisciplinarity' as a desired methodology for large research projects, it may not be clear what is intended, either to the research team writing the proposal, or to the reviewers assessing the proposals and teams combined strengths. For our purpose we shall briefly introduce some definitions of academic collaboration.

Problem-oriented research frequently involves a multitude of disciplines, and is characterised by ontological, epistemological and methodological heterogeneity. The most limited form is multidisciplinary research. In order to study an object that transcends disciplinary boundaries, this form of research draws on several disciplines without challenging the disciplinary boundaries and with the major part of research activities carried out within the traditions and paradigms of each discipline. When the common research is finished, the researchers return to their respective disciplines as they are defined beforehand.

Interdisciplinary research is based on an integration of a number of disciplines into a coherent research cluster providing a new framework for understanding. The disciplinary interaction and integration takes place in all phases in the research process; framing of research issues, execution of research, and the formulation and analyses of results. Interdisciplinary research tends to challenge both the disciplinary boundaries and the dominating paradigms within the several disciplines participating. Interdisciplinary research within popular divides such as the 'hard' or the 'soft' sciences is called moderate interdisciplinarity, whereas interdisciplinarity across the traditional divides is called radical interdisciplinarity. This could also be referred to as the difference

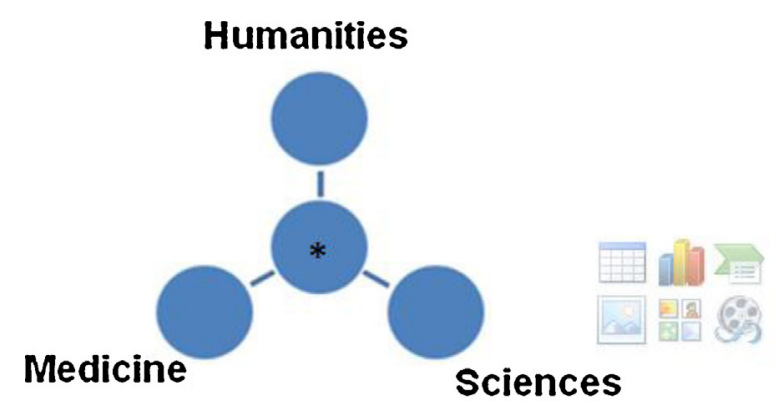

* Library, Admin

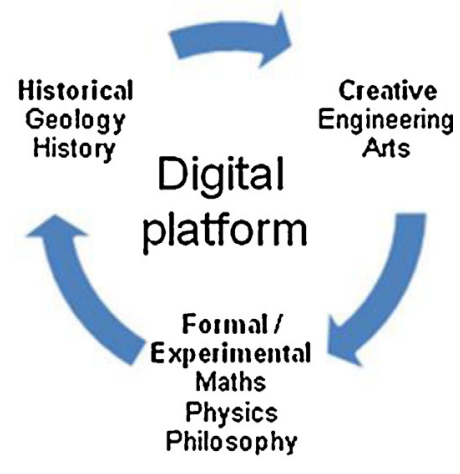

Fig. 1 - The University Challenge. Disciplinary knowledge production is based on a division of labour along faculty and disciplinary divides which are detrimental to radically interdisciplinary research. Central shared facilities are typically restricted to library and administrative functions. The RITE framework is based on the observation that disciplines are converging, blending data and information across disciplinary divides, based on a shared digital platform. 
between 'deep' and 'shallow' interdisciplinarity as exemplified by the concept of 'deep' and 'shallow' ecology.

The concept of transdisciplinarity is used by us to imply inclusion of other forms of knowledge than scientific knowledge in the research process; in a moderate form with actors outside academia taking part in the research process, or in a more radical form with lay knowledge given the same status and importance in research. This implies to erase the boundaries between science and society at large, also as regards to the knowledge produced. In this most radical form the concept of postdisciplinarity is applied. It must be noted that transdisciplinary science may raise the challenge of conceptions of post normal science. While normal science (as elaborated by Kuhn, 1962) maintains the desire or aspiration of science to approximate truth, post normal science (Funtowicz and Ravetz, 1991) dispenses with this aspiration given that inquiries may be dictated by urgency, and solutions required despite facts are uncertain. In such situations extended peerreview drawing on non-scientific stakeholders may become necessary. However, the dangers of post-normal science practices have been highlighted recently (Scholz, 2011).

Translational research denotes the value chain of research from conceptualisation, through empirical and archival work to generalisation and model building through to end-use and is usually supported by institutional support structures and funding models. While this form of funding and support is widespread in medical science it is not yet fully endorsed by GCR communities. In the theory of science literature, this concept is referred to as transactional research - which only partly relates to the long tradition of action research. It is important in our view that translational research is understood not just as transferring research results but is engaged in real collaborative processes.

A report on research collaboration and stakeholders found that multidisciplinary collaboration is much more likely to happen between disciplines which are relatively close to each other, such as within experimental sciences, or within geosciences, or within the humanities or within the social sciences than across the faculty divides (DEA, 2008). Collaboration across faculty divides is typically occurring at research institutes rather than at Universities. The Finnish Meteorological Institute (FMI) for example, has Economists employed. While the first type may be defined as constrained interdisciplinarity, the second and rarer type may be called radical interdisciplinarity (DEA, 2008). Collaboration between the human and natural sciences, which would be an example of radical interdisciplinarity, is one of the prime needs to successfully advance and improve the current state of interdisciplinary research in GCR.

International GCR programmes have not adequately conceptualised the potential of interdisciplinarity for their grand research questions and in particular have not fully addressed the question how to integrate human and social sciences with the natural sciences. They do, however, aim to provide a platform for interdisciplinary or integrative research which in principle they value highly. A common analogy may be made when comparing the efforts in addressing the fight against cancer with the type of efforts required for successfully mitigating human release of greenhouse gasses and adapting to a changing climate. These efforts not just involve transdisciplinary research but innovation along the entire value chain of the research efforts.

\section{HOW RITE?}

The overarching challenge is to build radically interdisciplinary research environments. Because:

- Complex problems increase the need to muster all relevant knowledge bases.

- Knowledge growth is so much larger by adding another discipline than by adding more resources to a discipline which is already engaged.

To best overcome the obstacles to interdisciplinary research while proactively taking advantage of the opportunities in such research and education, we propose a framework model to allow national and international funding programmes to envision and apply (to scientific programmes) a Radically Inter- and Trans-disciplinary research environment, which we have argued is the best type of environment to foster long-term success. In line with the objectives of our framework we call our model the Radically Inter- and Transdisciplinary Environments (RITE) framework for European Global Change Research (GCR).

The RITE framework prescribes that natural, technical, social, and human sciences should be integrated from day one. None of these sciences should be hegemonic, in other words it is important that not one science or discipline maintains a prerogative when developing a research programme. In particular it is important in GCR that other perspectives than natural sciences are allowed to identify research priorities which are aligned with fundamental research questions within their disciplines in order to develop GCR as a research field at the cutting edge.

To understand and cope with Global Change we need to harness all fields of human knowledge (Fig. 2). Scientific division of labour means that knowledge is compartmentalised in different reference systems but the challenges of sustainability, impacts, resilience, vulnerability, adaptation, mitigation is best accomplished via dialogue across reference systems.

The RITE framework attempts to develop a translational research strategy/model for GCR. The translational research model is already used in medicine to ensure a seamless path from bench to bed, from biomedical science to patients. Within RITE it would mean that the Earth is the patient that should be kept healthy and not just healed. The direct analogy to Global Change or Global Environmental Research is to frame this in terms of sustainability or resilience while taking into account climate change impacts, scarcity of energy and natural resources, societal vulnerability, mitigation, adaptation with the aim of developing a sustainable society.

The RITE framework would take us beyond rational choice theory and behavioural decision theory towards understanding

- Different attitudes towards nature, technology, and risk.

- Different conceptualizations of time and differential discounting of future outcomes. 


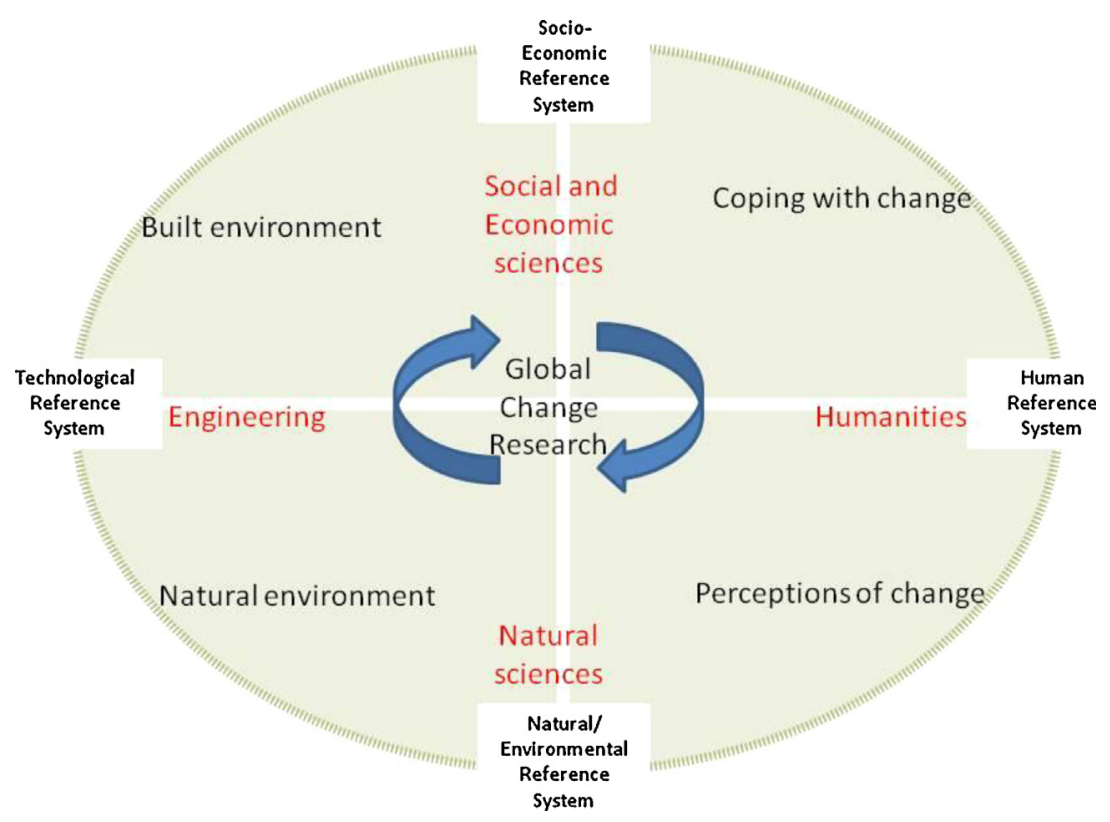

Fig. 2 - The reference systems of Global Change Research.

- Different strategies for arriving at "rational" decisions.

- Different rates of pro-social behaviour in common-property resource dilemmas.

To summarise, a radical interdisciplinary approach offers various innovations to GCR. A common framework or model needs to be developed to better enable interdisciplinary education and research in the GCR communities. There is no acceptable reason that we are not conducting translational research as well as our colleagues in the health professions.

\section{Interdisciplinarity and research funding}

Cooperative and integrative efforts in Global Change Research are nothing new. From the earliest reports to the Club of Rome (Meadows et al., 1972) research has combined the insights of many disciplines, and it would probably be reasonable to say that not one of the disciplines engaged in GCR is self-contained within its own disciplinary confines.

Collaboration in research is reflected in and supported by funding for collaborative research. Among many funding mechanisms available for European research, the European Framework Programme probably more than any other single mechanism has contributed to bring together nearly all natural and social science disciplines in integrative efforts while the European Framework Programme with the exception of the ERC may be said not yet to have fully harnessed the human sciences as well as certain parts of other basic sciences highly needed for successful GCR. New funding programmes such as the British Research Council programme Living With Environmental Change (LWEC) promises to increase funding for radical interdisciplinarity as it programmatically cuts across all disciplines and there are good examples of successful interdisciplinary collaboration for International Polar Year projects.
A number of reports for the EU Directorate General for Research have recommended increased funding for interdisciplinary research, while also deplored the inadequacy of current levels of integrated research responses to grand challenges. The METRIS report highlighted the unfulfilled potential of human and social science for Global Change Research and commented "The type of interdisciplinary research that is often needed to tackle major academic or industrial issues cut across the distinction between the natural and the social sciences and, increasingly, the humanities: climate change or pandemics, for instance, are issues that necessitate a wide-ranging cooperation between natural and social scientists. This requires 'deep' forms of interdisciplinarity that are achieved rather than given and require significant efforts from researchers"' (Holm et al., 2009, p. 35).

A survey of Danish interdisciplinary research environments showed that they attract double as much funding per researcher $(434,000 \mathrm{DKK})$ than monodisciplinary $(274,000$ $\mathrm{DKK})$. Interdisciplinary environments are also far better at attracting international partners $(80 \%$ of interdisciplinary groups have international partners versus $40 \%$ of monodisciplinary groups), and they receive double as much international funding $(67,000$ versus $34,000 \mathrm{DKK})$. However, most of interdisciplinary research is done within the comfort zone of traditional faculty divides, and less than $10 \%$ of all Danish research environments collaborate across "hard" and "soft" sciences. These radically interdisciplinary environments find it difficult to attract national funding, as only $5 \%$ of research council-funded projects are in this field. However, research council interest in the field of radical interdisciplinarity has grown 12\% from 2001 to 2005 (DEA, 2008).

In many systems there is a gap between political will and declarations of good intentions and their implementation. Some funding agencies are or have grown to become large, bureaucratic institutions that need more than one legislative 
period to adjust their policies, funding scheme criteria and processes, etc. The need to follow the political intention combined with the path dependency and (negative) resilience of an administrational system, results in tensions within funding schemes. For example, the German funding agency, DFG (its senior staff and leadership) is well aware of the need for interdisciplinary research and the need for innovative dynamic structures for this to be implemented. German policy also requires this. However, changing the funding schemes is a complex administrative procedure (white papers, consultations, drafts, approvals from various committees). As a result, "interdisciplinary" is simply added to the list of criteria for funding schemes basically developed to support and initiate disciplinary research (i.e. the list of criteria becomes inconsistent).

An additional problem is that the review process, crucial to the quality of research, needs (often voluntary) reviewers. The pool of reviewers does not yet reflect the interdisciplinary requirement. Hence it happens, that sophisticated interdisciplinary proposals are rejected based on the review of a reviewer not aware of what constitutes quality and innovation in interdisciplinary research.

As a result of the above, funding agencies likely need a self reflection process, an evaluation and assessment process, and subsequently a redesign of their funding schemes as well as their administrative processes (including adjusted qualification profiles for staff and reviewers, etc.) as well as re-thinking the division in standing committees, etc. since if there are only disciplinary committees, one cannot expect interdisciplinary proposals to be taken seriously. Positive action in this direction has taken place in a number of countries but further and deeper reforms are needed.

To prevent misunderstanding: Funding agencies should not get rid of disciplinary research funding schemes - these are important as well. We argue that interdisciplinary funding needs different structures and procedures than mono-disciplinary funding.

\section{The value of human and social sciences to Global Change Research}

A schism in funding exists between targeted and fundamental research. While the early European framework programmes for research aimed at "elucidating decision-making in future by developing a shared knowledge base on the challenges facing Europe" (Council decision for TSER Programme, 1994), the focus of the current Framework 7 has changed towards "grand challenges". A recent study of the Framework Programmes observed that they have generally shifted from being primarily mission-oriented (orientated towards promoting European economic competitiveness) towards being diffusion-oriented, providing support of building research capacity (Kastrinos, 2010).

However, the same study found that in the realm of the social sciences and humanities funding is still largely aiming at targeted mission-driven research funding. This discrepancy may explain some of the difference of attitude towards European funding which is often expressed in European research policy fora where human and social scientists tend to be more critical of constraints. While natural scientists may sometimes simply request of the human and social scientists to put a human and (more often) monetary value to consequences of technology and environmental change, the human and social scientists find it difficult to get funding for research which is driven by human and social science research questions.

This tension is clearly articulated by the chairperson of the European Research Council, Dr. Helga Nowotny: "The quest for relevance in the social sciences triumphed during the midtwentieth century, celebrating planning, social engineering and foresight. Its latest embodiment is the belief in evidence-based policy. Yet, it is often difficult to discern which kind of evidence counts in a given situation, whose evidence is to be used, and for what purpose.... Shifting from relevant knowledge to socially robust knowledge includes multiple, even contradictory, perspectives" (Nowotny, 2010, pp. 320-321).

The future of radical interdisciplinary research collaboration between the natural and human and social sciences depends on acknowledging Nowotny's analysis. Cooperation should not be based on the simple notion of "making use of another discipline" but be based on real cooperation right from the start, allowing each of the disciplines involved to articulate research questions from within a disciplinary perspective as well as without. This involves acknowledging that a multiplicity of viewpoints actually helps future proof research rather than hinders it. The uncertainty, contingency, and experimentation necessarily characteristic of Global Change Research may generate emergent forms of practice that require new approaches and radically new alignments through shared encounters (Yusoff, 2010; Gabrys and Yusoff, 2011). It also suggests that there are relative inequalities in "where we meet" as disciplines that need to be addressed in how we meet, on whose terms, with what resources, etc.

This should go hand in hand with a paradigm change in GCR with much more of a focus on human agency and practice. Understanding the Anthropocene can build on much recent work done in the social and human sciences about the relationship between human practice and the 'enframing' of environments, about the way value systems and identities shape attitudes and actions. There is also a viewpoint advanced about the relationship between nature and culture (now termed "naturecultures" - Haraway, 2003), new discourses of nature, and science as a social discourse, which critically examines how practices, values and imaginations shape material and social actions. This viewpoint emphasises the need to depart from the dualism nature - culture and arrive at a clear understanding of the co-evolution of humans and the natural world, which is being continually reshaped by human 'arrangements' and networks (from gardens and fields to modern transport systems) (Schatzki, 2003; Winiwarter and Schmid, 2008).

More generally, politicians, planners and managers need to accept that we cannot predict, by rational or scientific methods, the future growth of our scientific knowledge and we cannot, therefore, predict the future course of human history (Popper, 1963, pp. ix-x). To the degree that science is asked to address not only questions of what-we-know (episteme) and how-to-do (techne) but also questions of values and power (phronesis), scientists are exposed to challenges of public discourse and dialogue which are themselves new fields of social science research (Flyvbjerg, 2011). 
The exposure of single disciplines to broader questions of sustainability by itself helps single disciplines to advance beyond established ways of thinking. Learning from hard won experiences the economics discipline is gradually crawling out of its box admitting that the human cannot be usefully perceived as a homo oeconomicus and does not - at least not solely - take decisions inscribed in rational behaviour. This realisation is accompanied by an equally sour acknowledgement that markets and prices are not perfect reflections of scarcity because they are influenced by economic irrational behaviour. The Institute for New Economic Thinking may be seen as one such powerful example of a discipline wilfully trying to rethink its own premises based on real-world problems (http://ineteconomics.org/). On the other hand, psychology is a discipline which is becoming increasingly indispensable for studying responses to adaptation, willingness, frames of thinking, and cultural and cognitive factors (Scholz, 2011, pp. 162-164). In Europe work such as that of Forschunggroup Umwelt Psychologie springs to mind (http:// www.fg-umwelt.de/).

Significant progress has been made in disciplines such as history and archaeology by combining studies of historical records with environmental and ecological sciences (Winiwarter et al., 2004). Examples are projects like CLIWOC (weather data from naval observations 18th century - now also a project in the Global Environmental Change (GEC) programmes (http://www.ucm.es/info/cliwoc/; accessed 05.09.10) and (Hibbard et al., 2010; Costanza et al., 2007), and HMAP (historical information about marine population abundance and dynamics) (Holm et al., 2010). Similarly, progress has been made in combining valuations based on economic, social and cultural as well as biological criteria for areal management (Beaumont et al., 2007). An integrated field of landscape research is now taking shape with a very wide inter-disciplinary basis, that creates a good and timely opportunity for human interactions and underlying value patterns to become as well-understood by policy-makers as natural processes currently are. This interdisciplinary field can qualify feedbacks in nature by framing them in cultural and social dimensions, and the ecosystems approach can be made more powerful by proper recognition of the cultural foundation of present-day natural processes (Agnoletti, 2006; COST-ESF Science Policy Briefing 41). A recent audit in the field of 'environmental humanities' (180 members of the Consortium of Humanities Centres and Institutes around the globe) identified initiatives related to environmental and climate change in more than 60 centres (http://chcinetwork. org/about/). This new and strong trend is firmly embedding humanities-driven questions in a dialogue with natural and social sciences.

The EU METRIS report draws attention to the potential of increased radical interdisciplinarity: "Long-term historical analysis not only benefits from but also contributes to the natural sciences, especially in the fields of climate changes, landscape, environment, and conservation. While environmental sciences often rely on relatively recent information from empirical collection and testing, history and archaeology are able to provide baselines for biodiversity and population change on centennial and millennial scales. In recent years, these new interdisciplinary approaches have led to the revision of public conservation and management strategies. Similarly, we may see an increased interest in the understanding of public perceptions, reactions, and resilience to environmental change in coming years which may be informed by comparative research in social science and humanities, from economics to philosophy and literature studies" (Holm et al., 2009, p. 56).

\section{A new vision of interdisciplinary research}

Above we have listed some examples to show that interdisciplinarity is beneficial but how do emerging researchers become interdisciplinary without hurting their career? What concrete new forms of interdisciplinary research may be proposed?

The balance between "classical" discipline-based research and inter-disciplinary research has not yet been resolved. Disciplinary experts are needed with interdisciplinary experience based upon the experience of interdisciplinary GCR groups. We refer to the analogy of sports: the best sports players are generally world-class at their own position or just "doing what they do best" - on a team they have the capability of adding to team synergy. In other words, a striker on a football team would likely not have the same success as a defender. Conversely, while many sprinters are recruited to be riders on a bob-sled team, they would nearly never be asked to be the pilot or the brakeman of the bobsled. But how are the best coaches or managers trained? In the world of collaboration the "team" is the collaborative effort. To get it to play in synergy, a coach with extensive collaboration experience is needed, yet one who understands and knows that although they set the system and strategy based on the challenges of the game, they would never micro-manage a talent on the field. Similarly, being part of a team is an attitude. A football team of 11 individuals - who play as individuals instead of maximising on their own strengths in synergy with the strengths of their teammates, no matter how talented will fail.

The problem may be that academic research prioritises single-lens in-depth study while multi-lens perspectives need to be assessed against an excellence standard which is not available - or not in use to this point.

\subsection{New forms of interdisciplinary research}

Institutional efforts to establish infrastructure and strategy to advance interdisciplinary research should be welcomed. We believe, however, that so far radical interdisciplinarity is a very rare thing to occur and does not have the impact one would hope for. There is a need for an incentive system from the individual scientist to the international program level, encouraging risk taking and collaborative research. Funding agencies should become even more proactive and risk willing in order to develop such an incentive system.

The UK Sandpit model is an inspiring model to address the types of issues required of the multidisciplinary environment. "A sandpit is an intensive, interactive and free thinking workshop event, where a diverse group of scientists from a range of disciplines get together to immerse themselves in an exciting collaborative thinking process in a creative environment to uncover innovative solutions and prepare research 
proposals. ... The sandpit will be led by a Director who will be assisted by independent advisors and professional facilitators" (http://www.nerc.ac.uk/research/programmes/uncertainty/ events/sandpit.asp; 05.09.10). The strength in the Sandpit exercise documented above, lies in the commitment from the funding agency for a positive outcome, in that "NERC has allocated up to $£ 1.4 \mathrm{~m}$ (where this is $80 \%$ of the Full Economic Costs) to fund research arising from the sandpit event".

The Sandpit model is so far a national initiative only and largely restricted to the natural sciences. It is, however, scalable to an international level and if fully extended to the human and social sciences could be a very useful model for the future. At the European level it might be argued that the ESF and COST forward-looking initiatives contain some of the virtues of the Sandpit model but so far they have not focussed on Global Change Research and they come with no guarantee of future funding which means that the outcome of relevant exercises such as the European Landscape Science Policy Briefing has been minimal so far (COST-ESF Science Policy Briefing 41).

It is widely accepted that top down incentives in general only work at top notch institutions with high quality scientific leadership but are not always bottom-line cost effective or provide an immediate return on investment, but they do add great value to the local, national and international society. Examples of such a top down initiatives that are positively contributing to interdisciplinary collaboration are the Chalmers University of Technology Areas of Advance (http:// www.chalmers.se/en/sections/about_chalmers/advance; accessed 05.09.10) or the ETH - Zurich Centres of Competence and interdisciplinary scientific centres. The former defines an Area of Advance in a manner utilitarian to future thought for universities: "An Area of Advance must represent a field of strength at Chalmers on all 3 sides of the knowledge triangle; research, education and innovation. Secondly, the area must represent an opportunity, small or large, to improve the sustainability of our world. This is our source of incentive. And last but not least, there must be initiative-people with ideas of how to bring these resources together in a new and meaningful way".

Though these initiatives need to be people driven by a team of engaged scientists, the host institutions must empower and foster their creation and there must always be strong leadership of each initiative. Many of theses concepts are not new. Jantsch (1972) developed these in his work.

\subsection{Training of interdisciplinary researchers}

While we have documented, and indeed the authors of this report have, successful interdisciplinary careers, there are presently perceived challenges by many researchers (Pardo et al., 2008) with respect to interdisciplinary career prospects, especially those related to curiosity driven research. There is a lack of positions and prestige once a scholar ventures outside their discipline and this translates into difficulty gaining research funds. Without an associated training programme, it is difficult to attract students so there is a negative cycle that must be broken with respect to interdisciplinary training.

As an example, if you want to train a new generation of humanities scholars (historians, literary scholars, philosophers) to address questions of GCR you cannot train them using the methods of the past generations. The scholars must be aware of how different disciplines manage, interpret and produce data - we need to create practitioners who understand each other's processes and can therefore find common meeting places with those differentiated research methods and practices and gain synergy from this meeting of the minds. Similar demands will apply to the training of natural, health, social and polytechnical scientists. An excellent example of an interdisciplinary research training programme is documented in the literature (Evans and Randalls, 2008). It is difficult to predict future success, but certainly the ESRC-NERC programme demonstrates that gaps may be "bridged" and success may be found in training the future research generations that need to identify further gaps and bridge them.

Key to training of interdisciplinary researchers is instilling them with the ability to reflect on their work and team: Every successful interdisciplinary group communicates on the meta-level (e.g. "How is our communication impeded by disciplinary barriers, what exactly has hampered them today?"). In order to be able to perform such tasks, groups need a basic knowledge of epistemological and STS (social science and technology studies) issues. They also need to know where in society they stand, what possible political implications of their work will be so they can develop a proactive attitude towards the use of their knowledge. In addition to this, up and coming academics intent on collaboration must be provided with a mentor to be encouraged to develop an entrepreneurial spirit of risk taking as opportunities arise.

\subsection{Industry and developmental research}

We need programmes that can facilitate and enable transdisciplinary research. At this stage a special effort must be made to develop a dialogue with industry active in fields related to global change. This applies in particular to the private sector in green technology, renewable energy, and information, communication and technology but also for companies dealing with natural hazards including re-insurance companies and those building major new infrastructure. Access to industrial infrastructure, in particular laboratories, computing and modelling facilities as well as data generated as a result of industrial R\&D Activities represents a wealth of material that researchers should tap into in public-private partnerships focussed on interdisciplinary areas that will assure development and creation of new lead markets for the region. To do this, we must ensure that interdisciplinary research and training should not just take place in either academic or industrial environments, but occur across these environments in cooperation with one another.

\section{Recommendations for next steps}

In order to implement the recommendations in this paper, a pan European science policy programme must be developed to empower RITE. We believe that RITE is a significant, specific, and ambitious vision for interdisciplinary research, building on the strength and contribution of mono-disciplinary 
research. The goals for RITE are attainable, achievable and should be acceptable by the GCR community. Actionoriented goals with respect to RITE implementation need to be agreed upon by the funding agencies. The programmes must be realistic within the mandate of the funding framework as well as provide relevant results given a reasonable investment.

An educational system must be developed that is closely coupled to an attractive interdisciplinary research environment - many examples of success exist, but there are also examples where these interdisciplinary programmes fail. This is generally related to spreading the leadership, costs and responsibilities amongst too many actors.

GCR research needs schools with an international orientation that exploit traditional mono-disciplinary strengths to produce interdisciplinary researchers and interfaces between them from a very early stage of their career development. By providing critical mass, they also widen the scope of young researchers exposing them to high-level expertise and experience often not accessible to them through more traditional mono-disciplinary research training at a local level, because universities in their search for national prominence and proliferation often have a tendency to look inward. We find that multidisciplinary and interdisciplinary research across faculty divides happens when several obstacles are overcome. While adequate resources and incentives are necessary, institutional boundaries and disciplinary path dependency are often the key obstacles.

Mobility and PhDs granted by more than one European University is a European strength and should be built upon. We propose therefore that an interdisciplinary RITE doctoral training programme involving at least three universities should be created. It could be anchored at a virtual research centre, involving a consortium of interdisciplinary scientists across pan-European universities, or may be an educational arm of a European institution such as the EIT.

The RITE framework includes the need for a realignment of funding strategies to ensure that national and international research bodies and programmes road-map their respective strengths and identify areas for radical interdisciplinary research; then ensure that these areas can and are appropriately funded and staffed by talented individuals who want to apply their creative scientific talents to broader issues than their own field in the long term, rather than on limited scope $(5$ year and less) research projects. New fora and networks for successful collaboration in and beyond the GCR circuit must be created and fostered in the long-term. This requires a concerted collaborative effort between public and private stakeholders to ensure funding and career development are in place.

The way to measure the success of the recommendations proposed will be through volumes of interdisciplinary funds for programmes and training programmes focused on radical transdisciplinary research within GCR. RITE programmes will be results-oriented. In order to ensure alignment with major national, European or pan European research or GCR strategies any GCR RITE programme must provide timely results for use in strategic knowledge publications such as the IPCC reports. Thus the results provided will be tangible and traceable via citation and use in the GCR field.

\section{Acknowledgements}

The authors acknowledge Professor Karl George Høyer, Oslo University College, for his contribution to his discussion on definitions (see also Bhaskar et al., 2010) and to other members of RESCUE for their discussion, which contributed to the development of this article.

\section{REFEREN C E S}

Agnoletti, M. (Ed.), 2006. The Conservation of Cultural Landscapes. CAB International, Wallingford/New York. Beaumont, N., Austen, M., Atkins, J., Burdon, D., Degraer, S., Dentinho, T., Derous, S., Holm, P., Horton, T., Ierland, E.V., Marboe, A.H., Starkey, D.J., Townsend, M., Zarcyski, T., 2007. Identification, definition and quantification of goods and services provided by marine biodiversity: Implications for the ecosystem approach. Marine Pollution Bulletin 54 (3), 253-265.

Bhaskar, Roy, Frank, Cheryl, Høyer, Karl Georg, Naess, Petter, Parker, Jenneth (Eds.), 2010. Interdisciplinarity and Climate Change. Transforming Knowledge and Practice for Our Global Future. Routledge, London.

Biermann, Frank, Betsill, Michele M., Gupta, Joyeeta, Kanie, Norichika, Lebel, Louis, Liverman, Diana, Schroeder, Heike, Siebenhüner, Bernd with contributions from Conca, Ken da Costa Ferreira, Leila, Desai, Bharat, Tay, Simon, Zondervan, Ruben, 2009. Earth System Governance: People, Places and the Planet. Science and Implementation Plan of the Earth System Governance Project. Earth System Governance Report 1, IHDP Report 20. Bonn, IHDP: The Earth System Governance Project (see IHDP reference below).

Cloetingh, S., Ziegler, P.A., TOPO-EUROPE team, 2007. TOPO-EUROPE: the geoscience of coupled Deep Earth and surface processes. Global Planet Change 58, 1-118.

Costanza, R., Graumlich, L., Steffen, W., Crumley, C., Dearing, J., Hibbard, K., Leemans, R., Redman, C., Schimel, D., 2007. Sustainability or collapse: what can we learn from integrating the history of humans and the rest of nature? Ambio 36, 522-527.

COST-ESF Science Policy Briefing 41. Landscape in a Changing World. Bridging Divides, Integrating Disciplines, Serving Society, October 2010.

DEA, 2008. Thinking across Disciplines - Interdisciplinarity in Research and Education. Danmarks ErhvervsforskningsAkademi: http://www.dea.nu/sites/ default/files/Thinking\%20Across\%20Disciplines\%20-\%20 Interdisciplinarity\%20in\%20Research\%20and\%20Education 0.pdf.

Evans, J., Randalls, S., 2008. Geography and paratactical interdisciplinarity: views from the ESRC-NERC PhD studentship programme. Geoforum 39, 581-592.

Flyvbjerg, B., 2011. Making Social Science Matter. In: Papanagnou, G. (Ed.), Social Science and Policy Changes. UNESCO Research and Policy Series, Paris, pp. 25-56.

Funtowicz, S.O., Ravetz, Jerome R., 1991. A new scientific methodology for global environmental issues. In: Robert Costanza (Eds.), Ecological Economics: The Science and Management of Sustainability. Columbia University Press, New York, pp. 137-152.

Gabrys, J., Yusoff, K. 2011. Arts, sciences and climate change: practices and politics at the threshold in science as culture (available from authors). 
Gelfand, T., 1976. The origins of a modern concept of medical specialization: John Morgan's discourse of 1765. Bulletin of the History of Medicine 50, 511-535.

Haraway, D., 2003. The Companion Species Manifesto: Dogs, People and Significant Otherness. Prickly Paradigm Press, Chicago.

Hibbard, K.A., Costanza, R., Crumley, C., van der Leeuw, S., Aulenbach, S., Dearing, J., Morais, J., Steffen, W., Yasuda, Y., 2010. Developing an Integrated History of People on Earth (IHOPE): Research Plan. International Geosphere-Biosphere Programme, Stockholm, p. 34.

IGBP - International Geosphere-Biosphere Programme, 2006. Brochure: Providing Scientific Knowledge to Improve the Sustainability of the Living Earth (Online at http://www. igbp.net/documents/IGBP-Brochure.pdf).

IHDP - International Human Dimensions Programme on Global Environmental Change, 2007. Strategic Plan 2007-2015. Framing Worldwide Research on the Human Dimensions of Global Environmental Change (Online at http://www.ihdp. unu.edu/file/public/WebStratPlan?menu=84).

Jantsch, 1972, 1972. Inter- and transdisciplinary university: a systems approach to education and innovation. The Journal of Higher EducationIn: http://www.springerlink.com/ content/p8642kgv28147372/ (accessed 05.09.10).

Holm, Poul (Chair), Guilhot, Nicolas (Rapporteur), Dumitrescu, Dalina, Griffin, Gabriele, Jarrick, Arne, Rév, Istvan, Roll, Gulnara, Smilov, Daniel, Sztompka, Piotr, Thys-Clement, Françoise, Tsakloglou, Panos, Van Langenhove, Luk, Wolf, Gerhard, 2009. METRIS, Emerging Trends in Research in Social Sciences and Humanities, Office for Official Publications of the European Communities, European Commission, Luxembourg.

Holm, Poul, Marboe, Anne Husum, Poulsen, Bo, MacKenzie, Brian R., 2010. Marine animal populations: a new look back in time. In: McIntyre, A.D. (Ed.), Life in the World's Oceans: Diversity, Distribution and Abundance. Blackwell, Oxford.

Kastrinos, Nikos, 2010. Policies for co-ordination in the European Research Area: a view from the social sciences and humanities. Science and Public Policy 37 (4), 297-310.

Kuhn T.S. 1962, The Structure of Scientific Revolutions, Chicago. Lang, D., Wiek, A., Bergmann, M., Stauffacher, M., Martens, P., Moll, P., Swilling, M., Thomas, C.J., 2012. Transdisciplinary research in sustainability science - practice, principles, and challenges. Sustainability Science 7 (Supplement 1), 25-43.

Meadows, Donella H., et al., 1972. Limits to Growth: A Report for the Club of Rome's Project on the Predicament of Mankind. Universe Books.

Nowotny, H., 2010. Out of science, out of sync? In: World Social Science Report, UNESCO, Paris, pp. 319-322.

Pardo, M., et al. 2008. Barreras y Oportunidades para la interdisciplinariedad en la investigación sobre Cambio Global. University Carlos III of Madrid (Barriers and Opportunities for interdisciplinary research in Global Change).

Popper, Karl R., 1963. Conjectures and refutations: the growth of scientific knowledge. Routledge \& Kegan Paul, London.

Pearson, K., 1892. The Grammar of Science, London.

Reid, W.V., Chen, D., Goldfarb, L., Hackmann, H., Lee, Y.T., Mokhele, K., et al., 2010. Earth system science for global sustainability: grand challenges. Science 330 (6006), 916-917. van Rijnsoever, F.J., et al. 2011. http://rathenau.academia.edu/ LaurensHessels/Papers/358812/Factors_associated_with_ disciplinary_and_interdisciplinary_research_collaboration (accessed 03.07.11).

Schatzki, Th.R., 2003. Nature and technology in history. History and theory: studies in the philosophy of history. Theme issue 42. Environment and History 82-93.

Schellnhuber, H.J., Sahagian, D., 2002. The twenty-three GAIM questions. Global Change Newsletter 49, 20-21.

Scholz, R.W., Lang, D.J., Wiek, A., Walter, A., Stauffacher, M., 2006. Transdisciplinary case studies as a means of sustainability learning: Historical framework and theory. International Journal of Sustainability in Higher Education 7, 226-251.

Scholz, R.W., 2011, Environmental Literacy in Science and Society: From Knowledge to Decisions. Cambridge, U.P.

Spangenberg, J.H., 2011. Sustainability science: a review, analysis and some empirical lessons. Environmental Conversation 38, 275-287.

Winiwarter, Verena, Armiero, Marco, van Dam, Petra, Dix, Andreas, Eliasson, Per, Holm, Poul, Jelecek, Leos, Lambert, Robert A., Massard-Guilbaud, Genevieve, Gonzales de Molina, Manuel, Myllyntaus, Timo, Oosthoek, Jan, Pfister, Christian, Racz, Lajos, 2004. Environmental history in Europe from 1994 to 2004: enthusiasm and consolidation. Environment and History 10 (4), p501-p530.

Winiwarter, Verena, Schmid, Martin, 2008. Umweltgeschichte als Untersuchung sozionaturaler Schauplätze? Ein Versuch, Johannes Colers "Oeconomia" umwelthistorisch zu interpretieren. In: Knopf (Hg.), Thomas (Ed.), Umweltverhalten in Geschichte und Gegenwart. Attempto Verlag, Tübingen, pp. 158-173.

Yusoff, K., 2010. Biopolitical economies and the political aesthetics of climate change. Theory, Culture and Society 27 (2/3), 73-99.

\section{F U R THER RE A D I N G}

ESF INIF "The Future of Knowledge - Mapping Interfaces" http://www.esf.org/research-areas/humanities/strategicactivities/the-future-of-knowledge.html.

ESF 2010. Joint Round Table with Standing Committees' Core Groups and ESF Member Organisations "Grand Challenges and Interdisciplinarity: Opportunities for Member Organisations and ESF in the developing European Research Area" - http://www.esf.org/rt2010.

ESF-COST initiative on "Cultural Literacy in Contemporary Europe" - http://www.esf.org/research-areas/humanities/ strategic-activities/esf-cost-synergy.html.

Joint Workshop ESF-FWF-AHRC and Univ. of Vienna "Relevance and Impact of the Humanities" - http://www.esf.org/ research-areas/humanities/strategic-activities.html, see "Relevance and Impact of the Humanities".

ESF Humanities Spring 2007 - Young Researchers Forum "Disciplines and Borders: Humanities research in an age of interdisciplinarity" - http://www.esf.org/research-areas/ humanities/strategic-activities/humanities-spring.html, see "Humanities Spring 2007". 